\title{
Atık Baraj Yerindeki Kaya Kütlelerinin Mühendislik Özelliklerinin Değerlendirilmesi: Gümüşhane Örneği
}

\author{
Evaluation of Engineering Properties of Rock Masses in Waste Dam Site: The Example of \\ Gumushane
}

\author{
Selçuk ALEMDAĞ ${ }^{* 1, a}$, Mustafa KANIK ${ }^{2, b}$ \\ ${ }^{I}$ Gümüşhane Üniversitesi, Mühendislik ve Doğa Bilimleri Fakültesi, Jeoloji Mühendisliği Bölümü, Gümüşhane \\ ${ }^{2}$ Fırat Üniversitesi, Mühendislik Fakültesi, Jeoloji Mühendisliği Bölümü, Elazı̆̆
}

\begin{tabular}{|c|c|c|}
\hline - Geliș tarihi / Received: 15.02 .2020 & - Düzeltilerek geliș tarihi / Received in revised form: 12.04 .2020 & - Kabul tarihi / Accepted: 21.04 .2020 \\
\hline
\end{tabular}

\begin{abstract}
$\ddot{\mathbf{O} z}$
Bu çalı̧şmada Gümüştaş Atık Depolama Barajı II eksen yeri kaya kütlelerinin kazılabilirlik, taşıma kapasitesi ve geçirimlilik özellikleri değerlendirilmiştir. Atık depolama alanı hacminin arttırılmasına yönelik yapılacak kazı için, kaya kütlelerinin kazılabilirlik sınıfları andezitik breş için kırma yöntemi, andezit için ise kırma ve patlatma yöntemi olarak belirlenmiştir. Baraj eksen yeri temel kayası olan andezitlerin taşıma kapasitesi ampirik eşitlikler yardımıyla belirlenmiş olup, nihai taşıma kapasitesi 31.07MPa, izin verilebilir taşıma kapasitesi ise 10.44MPa olarak belirlenmişsir. Andezit ve andezitik breș kaya kütlelerinde açılmıș olan temel sondaj kuyularında yapılan basınçlı su deneyleri ve sonlu elemanlar yöntemi kullanılarak yapılan sızıntı analizi ile geçirimlilik değerlendirmesi yapılmış olup, temel kaya kütlesinin az geçirimli özellikte olduğu belirlenmiştir. Bu durum atık barajı rezervuar alanında biriktirilecek kimyasal atıkların yeraltı suyuna karışmasına sebep olacaktır. Bu sızmayı önlemek için baraj eksen yeri ve rezervuar alanına 35$40 \mathrm{~cm}$ kalınlığında geçirimsiz doğal kil malzeme serilip skkıștırılacaktır. Yapılan bu uygulama sonlu elemanlar yöntemi kullanılarak modellenmiș ve rezervuar alanı tamamen atık su ile dolduğu durum için yapılan sızma analizi sonucunda geçirimlilik değeri $5 \times 10^{-11} \mathrm{~m} / \mathrm{s}$ olarak belirlenmiştir. Ayrıca, temel kazısından $10 \mathrm{~m}$ derinlikte belirlenen deşarj kesitinde meydana gelen su kaçakları $1.69 \times 10^{-17} \mathrm{~m}^{3} / \mathrm{s}$ ile $3.44 \times 10^{-16} \mathrm{~m}^{3} / \mathrm{s}$ arasında değișmektedir. Bu değerler oldukça küçük değerler olup, yine de olası bir sızmanın meydana gelebileceğini göstermektedir. Bu muhtemel sızmayı ortadan kaldırmak için serilecek doğal kil tabakanın üzerine, jeotekstil malzemeler (jeosentetik kil membran, jeomembran ve drenaj jeokompozit) serilerek rezervuar alanı tamamen geçirimsiz duruma getirilmelidir. Böylece atık barajı rezervuar alanında flotasyon sonrası biriktirilecek olan kimyasal atık suyun yeraltı suyuna karışması önlenmiş olacaktır.
\end{abstract}

Anahtar kelimeler: Atık Barajı, Geçirimlilik, Kazılabilirlik, Sızıntı Analizi, Taşıma Kapasitesi

\begin{abstract}
In this study, excavatability, bearing capacity and permeability characteristics of rock masses along the Gümüştaş Waste Storage Dam II site were evaluated. For the excavations to be carried out to increase the volume of the waste storage area, the excavation classes of the rock masses were determined as "Hammer" for andesitic breccia and "Hammer\&Blasting" for andesite. The bearing capacity of andesite (bedrock) has been determined with the help of empirical equations and, allowable bearing capacity and ultimate bearing capacity were calculated as 10.44MPa and 31.07MPa, respectively. The permeability has been assessed by the Lugeon Tests conducted in the geotechnical drill holes located in the andesite and andesitic breccia rock masses and with the aid of the seepage analysis based on the finite element method the bedrock mass has been defined as low permeable. Low permeable rock masses would possibly cause the chemical wastes to be collected in the waste dam reservoir area to pollute the groundwater. To prevent the seepage, impermeable natural clay material of 35-40cm thickness should be laid and compressed along the dam axis and reservoir area. This suggestion was modeled with the aid of the finite element method, for the case that the reservoir area was completely filled with wastewater and, the permeability value was determined as $5 \times 10^{-11} \mathrm{~m} / \mathrm{s}$ as a result of the seepage analysis. In addition, seepage values in the discharge section at a depth of $10 \mathrm{~m}$ from the foundation vary between $1.69 \times 10^{-17} \mathrm{~m}^{3} / \mathrm{s}$ and $3.44 \times 10^{-16} \mathrm{~m}^{3} / \mathrm{s}$. These values are quite low but, are indicators of a possible seepage. To eliminate this possible seepage, the geotextile materials (geosynthetic clay membrane, Geomembrane, and drainage geocomposite) should be laid over the compressed natural clay layer, and thus mixing of the chemical wastewater, which collected after flotation, into the groundwater will be prevented.
\end{abstract}

Keywords: Waste Dam, Permeability, Excavatability, Seepage Analysis, Bearing Capacity

*a Selçuk ALEMDAĞ; selcukalemdag@gmail.com, Tel: 0(456)2331000, https://orcid.org/0000-0003-2893-3681

${ }^{\mathrm{b}}$ orcid.org/0000-0002-1019-5249 


\section{Giriş}

Barajlar tarih boyunca taşkın koruma, sulama, içme suyu sağlama ve enerji elde etmek gibi amaçlarla tasarlanmışlardır. Son 25 yıllık süreçte ise katı atık ve maden atıklarını biriktirme amacıyla da inşa edilmektedirler. Farklı kullanım amaçlarına göre tasarlanan baraj projelerinde inşa edilecek mühendislik yapılarına temel oluşturan kaya kütlelerinin dayanım ve geçirimlilik özelliklerinin belirlenmesi oldukça önemlidir. Özellikle atık barajı inşası planlanan bölgelerde rezervuar alanları için geçirimlilik analizi yapılması yeraltı suyu kirliliğinin önlenmesi açısından hayati önem taşımaktadır. Bu kapsamda birçok araştırmacı da (Wang vd., 1999; Karagüzel ve K1lıç, 2000; Foyo vd., 2005; Alemdag vd., 2008; Coli vd., 2008; Ersoy vd., 2008; Nandi, 2011; Gürocak ve Alemdağ, 2012; Noorzad ve Manavirad, 2012; Moosavi vd., 2012; Rad vd., 2013; Türkmen vd., 2013; Alemdağ, 2015; Kan1k ve Ersoy, 2019; Ersoy vd., 2019) önemli çalışmalar yapmışlardır.

$\mathrm{Bu}$ çalışmaların hassasiyetle yapılmasının önemi ise, 2019 yılının başında Brezilya'nın güneybatısında Minas Gerais eyaletinde y1kılan atık barajının birçok can ve mal kaybına, özellikle de çevre kirliliğine neden olmasıyla bir kez daha ortaya çıkmıştır.

Bu çalışmada, Gümüşhane ili, Harmancık köyü sınırları içerisindeki organize sanayi bölgesinde
Gümüştaş Madencilik ve Ticaret A.Ş. tarafından yapılması planlanan 2. atık depolama barajı (Şekil 1) gövde ve rezervuar alanında yayılım gösteren kaya kütlelerinin jeoteknik açıdan incelenmesi amaçlanmaktadır.

$\mathrm{Bu}$ amaçla baraj eksen yeri ve rezervuar alanında yayılım gösteren temel kayanın geçirimliliği yerinde deneyler ve sayısal analiz yöntemleri ile, taşıma kapasitesi ampirik eşitlikler yardımıyla, rezervuar alanı ve temel kayasının kazılabilirliği ise Jeolojik Dayanım İndeksi (GSI) dikkate alınarak belirlenmiştir.

Taşıma kapasitesi hesaplamaları için; Hoek vd. (2002) tarafindan önerilen $m_{b}$, $s$, a kaya kütle sabitleri belirlenmiş, bu değerler Kulhawy ve Carter (1992) ve Wyllie (1992) tarafindan önerilen taşıma kapasitesi eşitliklerinde kullanılarak, baraj eksen yeri temel kayasının taşıma kapasitesi hesaplanmıştır. Baraj ekseni ve rezervuar alanındaki kaya kütlesinin geçirimliliğinin belirlenmesi için, yerinde deneyler (basınçlı su testi) yapılmış ve bu değerler sayısal analizlerde girdi parametresi olarak kullanılıp, rezervuar alanı ve baraj eksen yerinin geçirimlilik durumu sayısal olarak da ortaya konmuştur. Ayrıca temel kotunun $10 \mathrm{~m}$ derinliği için çizilen deşarj kesitinde meydana gelecek s1zma miktarı RS2 (Rocscience, 2019) programında yapılan sızma analizi yardımıyla belirlenmiştir.
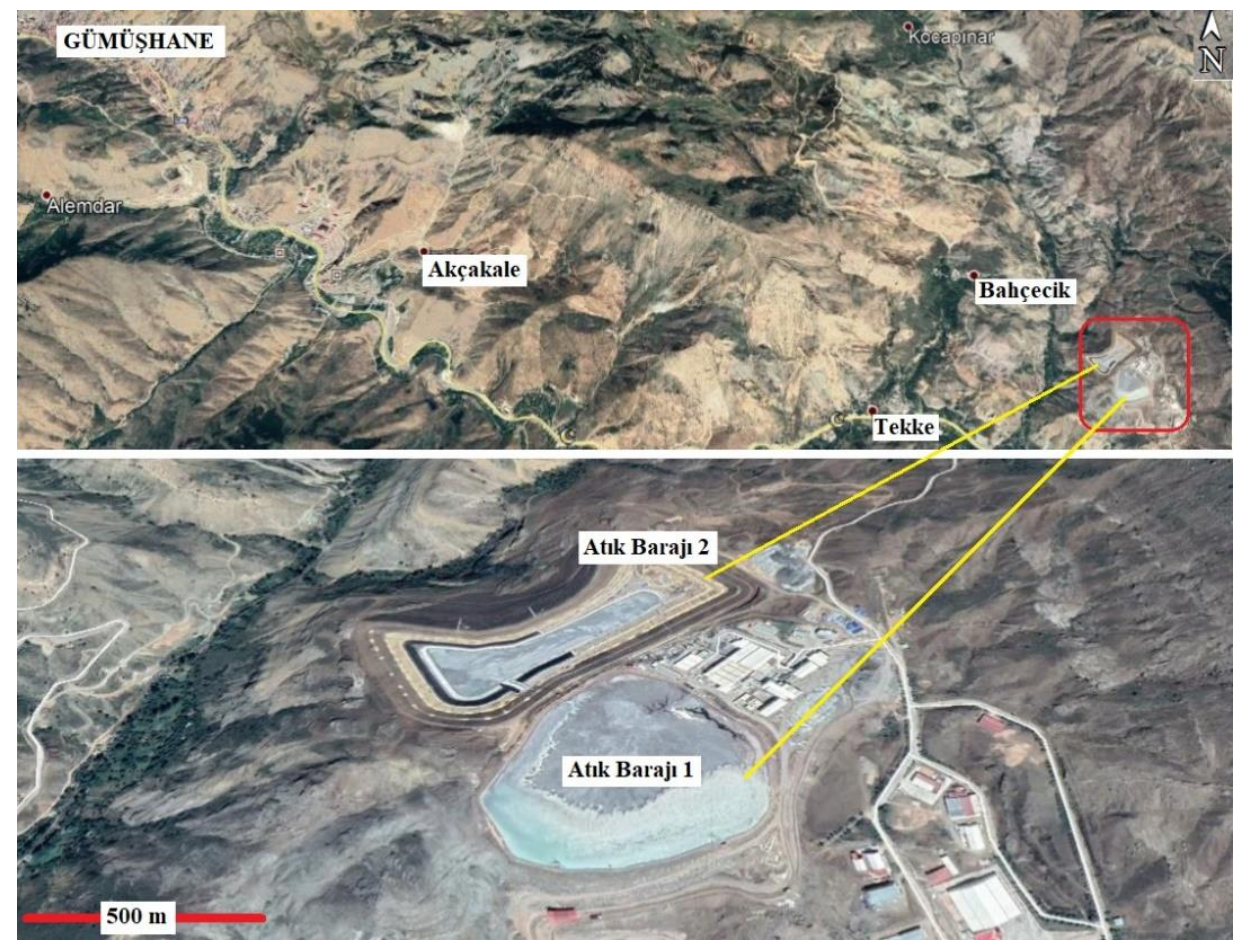

Şekil 1. İnceleme alanına ait uydu görüntüsü 


\section{Baraj Alanının Jeolojisi}

Baraj inşasının gerçekleştirileceği alanda Eosen yaşlı Alibaba Formasyonu yüzeyleme vermektedir (Şekil 2). Tekkeköy ve civarında yüzeylenen Alibaba Formasyonu üzerine açısal bir uyumsuzlukla Kermutdere Formasyonu gelmektedir. Alibaba Formasyonu, yersel olarak izlenen ince bir taban konglomeras1 ve nummulitli kumlu kireçtaşlarıyla başlar ve volkano-tortul istif özelliği taşır. Bunların üzerinde tabakalı tüfler, andezitik breşlerle ardalanmalı olarak bulunmaktadır. Genellikle arazide üst seviyelerde andezit, bazalt ve piroklastları şeklinde gözlenmektedir (Kaygusuz vd., 2011; Arslan ve Aliyazıcıŏlu, 2001). Baraj inşa alanı Alibaba
Formasyonu'nun üst seviyelerinde bulunan andezitik breş ve andezit birimleri içerisinde gerçekleştirilecektir. Topoğrafyada engebeli bir görüntü sunan andezitik breşler genellikle üst üste dizilmiş yastıklar şeklinde ve siyahımsı gri renklidir.

Ayrıca yamaç eteklerinde bulunan ve yamaçların bulunduğu alandaki kayaç türlerine göre köşeli, yass1 ve bazıları küt köşeli, blok, çakıl, kum, silt ve killerden oluşan yamaç molozları da çalışma alanında Alibaba Formasyonu üzerinde uyumsuz olarak gözlenmektedir. Buna ek olarak Kozevrez ve Kocapınar dereleri boyunca sığ derinliklerde $25-30 \mathrm{~cm}$ kalınlığına sahip alüvyon birikintilerine de rastlanılmaktadır.

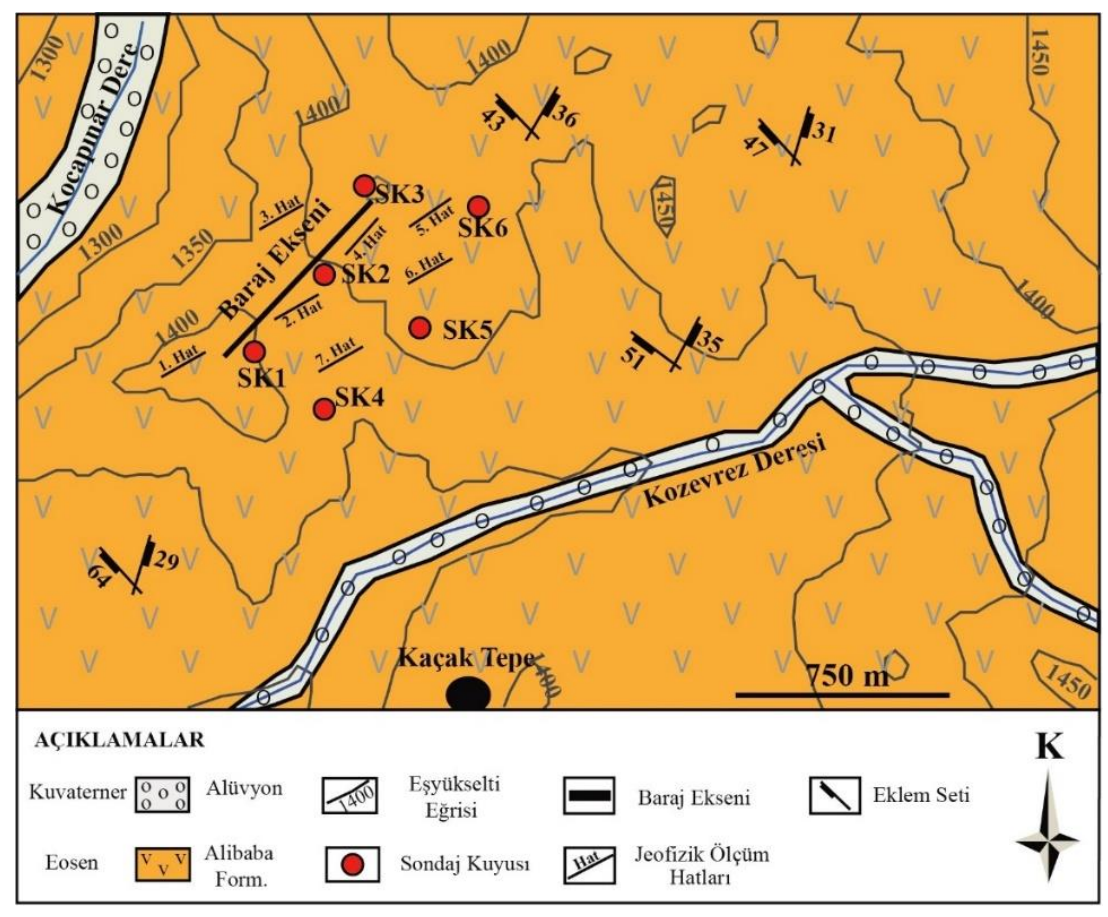

Şekil 2. Çalışma alanının jeoloji haritası

Gümüşhane civarındaki tektonik unsurlar genel olarak K-G yönlü bir sıkışmanın izlerini yansitmakta olup, bu durum kaya kütlelerinden alınan eklem yönelim ölçülerinin analizleriyle de ortaya konulmuştur (Gurocak vd., 2017; Bostanci vd., 2018). Buna ek olarak inceleme alanında aktif veya pasif bir fay bulunmamaktadır. Bölgeyi etkileyecek en önemli tektonik yap1 Kuzey Anadolu Fay hattı olup, çalışma alanına olan mesafesi yaklaşık $80 \mathrm{~km}$ civarındadır.

\section{Saha ve Laboratuvar Çalışmaları}

İnceleme alanında yapılan temel sondajlarının üç adeti SK1 (40m), SK2 (50m) ve SK3 (50m) atık baraj1 eksen yerinde, diğer üç adeti SK4 $(50 \mathrm{~m})$, SK5 $(58 \mathrm{~m})$ ve SK6 $(58 \mathrm{~m})$ ise rezervuar alanında yapılmıştır. Atık barajı eksen yerindeki birimlerin jeoteknik özelliklerini belirlemek amacıyla arazi çalışmaları kapsamında, andezitik breş ve andezit kaya kütlelerinin içerdiği süreksizliklerin mühendislik özellikleri ISRM (2007) tanımlama ölçütleri dikkate alınarak ve hat etüdü yöntemi kullanılarak belirlenmiştir (Tablo 1). Ayrıca laboratuvarda kaya malzemelerine ait jeomekanik özellikleri belirlemek için temel sondajlarından karot örnekleri derlenmiş (Şekil 3) ve ISRM (2007) tarafından önerilen yöntemlere göre karotlar hazırlanarak, deneyler Gümüşhane Üniversitesi Kaya Mekaniği Laboratuvarında 
yapılmıştır. Kaya kütlelerine ait RQD (\%) değerleri ise temel sondajlarından elde edilen karot örneklerinde (Şekil 3) yapılan ölçümler ile her bir kaya kütlesi için ayrı ayrı hesaplanmış ve istatistiksel dağılımları Şekil 4'de verilmiştir.

Tablo 1. Andezit ve Andezitik Breş kaya kütlelerinin süreksizlik özellikleri

\begin{tabular}{|c|c|c|c|}
\hline \multirow{2}{*}{ Süreksizlik özellikleri } & \multirow{2}{*}{ Tanımlama } & \multicolumn{2}{|r|}{ Puan } \\
\hline & & Andezit & Andezitik Breș \\
\hline \multirow{2}{*}{ Pürüzlülük } & Az pürüzlü & - & 3 \\
\hline & Pürüzlü & 5 & - \\
\hline \multirow[b]{2}{*}{ Bozunma } & Orta derecede bozunmuş & & 3 \\
\hline & Az bozunmuş & 5 & - \\
\hline Dolgu & Kalsit dolgu kalınlığı $2-4 \mathrm{~mm}$ & 4 & 4 \\
\hline Devamlilik & $3-10 \mathrm{~m}$ & 2 & 2 \\
\hline Açıklık & $0.1-1 \mathrm{~mm}$ & 4 & 4 \\
\hline JCond $_{89}$ & & 20 & 16 \\
\hline
\end{tabular}

Laboratuvar deneyleri ile andezit ve andezitik breşlerin ortalama tek eksenli basınç dayanımı ve birim hacim ağırlıkları belirlenmiștir. Deneylerden elde edilen tek eksenli sıkışma dayanımı andezitler için ortalama $54 \mathrm{MPa}$, andezitik breșler için ise 37MPa'dır. Birim hacim ağırlık değerleri andezitler için $26.87 \mathrm{kN} / \mathrm{m}^{3}$, andezitik breşler için ise $26.18 \mathrm{kN} / \mathrm{m}^{3}$ olarak belirlenmiştir. Andezit ve andezitik breşler için ortalama RQD değerleri sırasıyla \%81 ve \%35'tir.

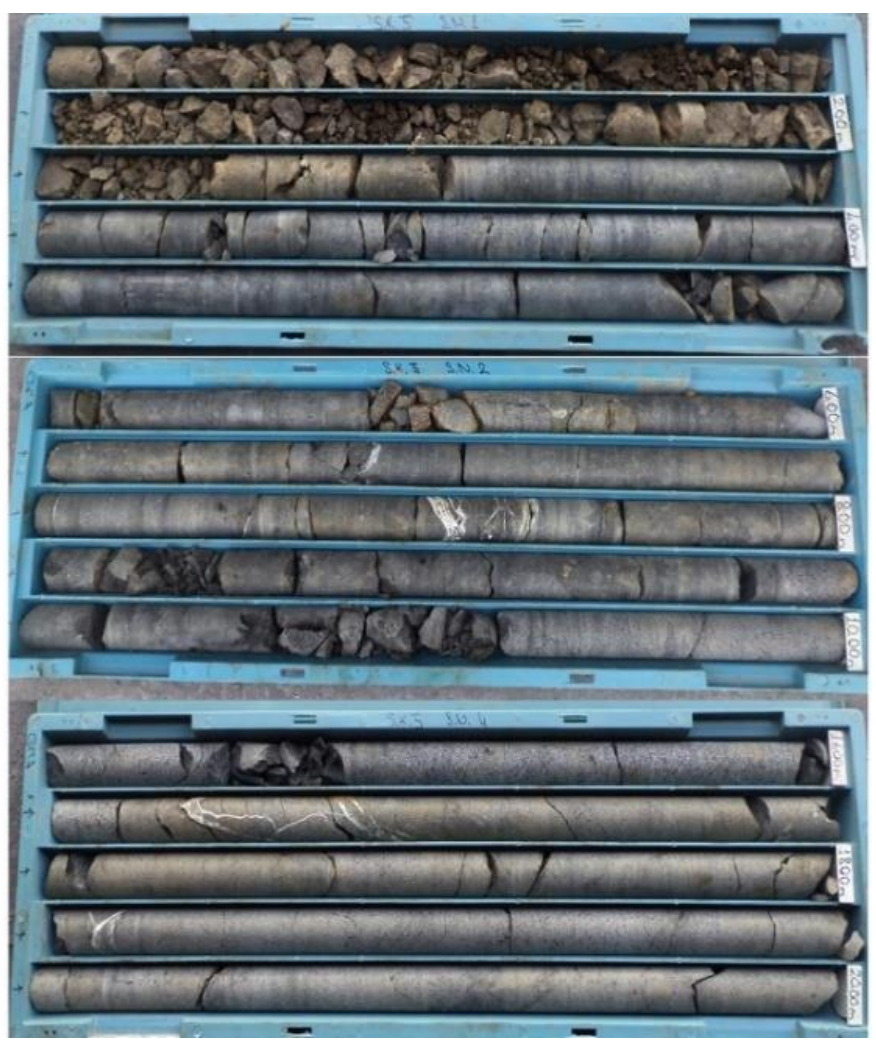

Şekil 3. Andezitik breş (ilk 2.5m) ve andezitlerin (SK-5) karot sandıklarında görünümü.

Baraj eksen yerindeki birimlerin kaya kütle kazılabilirliği ve dayanımını belirlemek amacıyla GSI sinıflama sisteminden faydalanılmıştır.
Andezit ve andezitik breş kaya kütlesine ait Jeolojik Dayanım İndeksi (GSI) değerini belirlemek için Hoek vd. (2013) tarafindan 
önerilen sayısal sınıflama abağı kullanılmıştır. Bu sinıflamada kullanılan $1.5 * \mathrm{JCond}_{89}$ (Süreksizlik durumu) değerleri Tablo 1'de verilmiş olup,

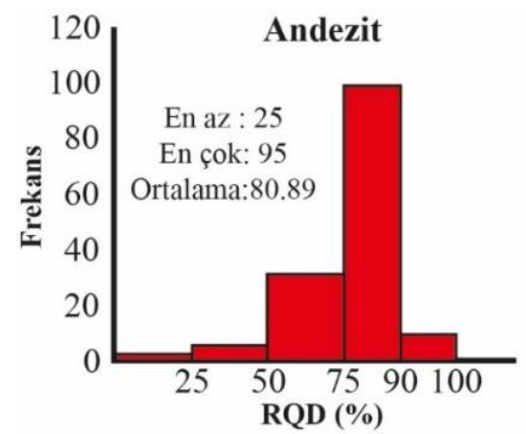

RQD/2 değeri Şekil 4'te verilen ortalama RQD değerleri kullanılarak belirlenmiştir.

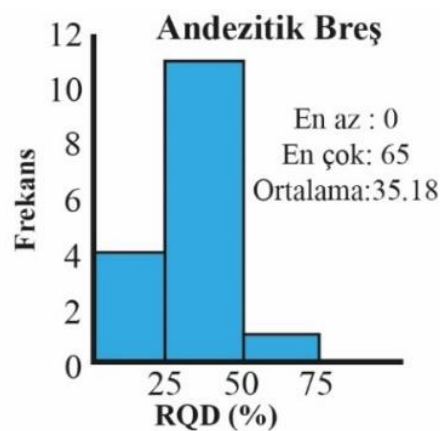

Şekil 4. Andezit ve andezitik breşler için RQD histogramları

Buna göre Andezit kaya kütlesine ait GSI değeri 64, andezitik breş kaya kütlesine ait GSI değeri ise 48 olarak belirlenmiştir (Şekil 5). Her bir kaya kütlesine ait sabitler $\left(\mathrm{m}_{\mathrm{b}}, \mathrm{s}\right.$, a) ise Hoek-Brown
(Hoek vd., 2002) yenilme kriteri dikkate alınarak, RocLab V1.03 (2007) programı ile hesaplanmıştır.

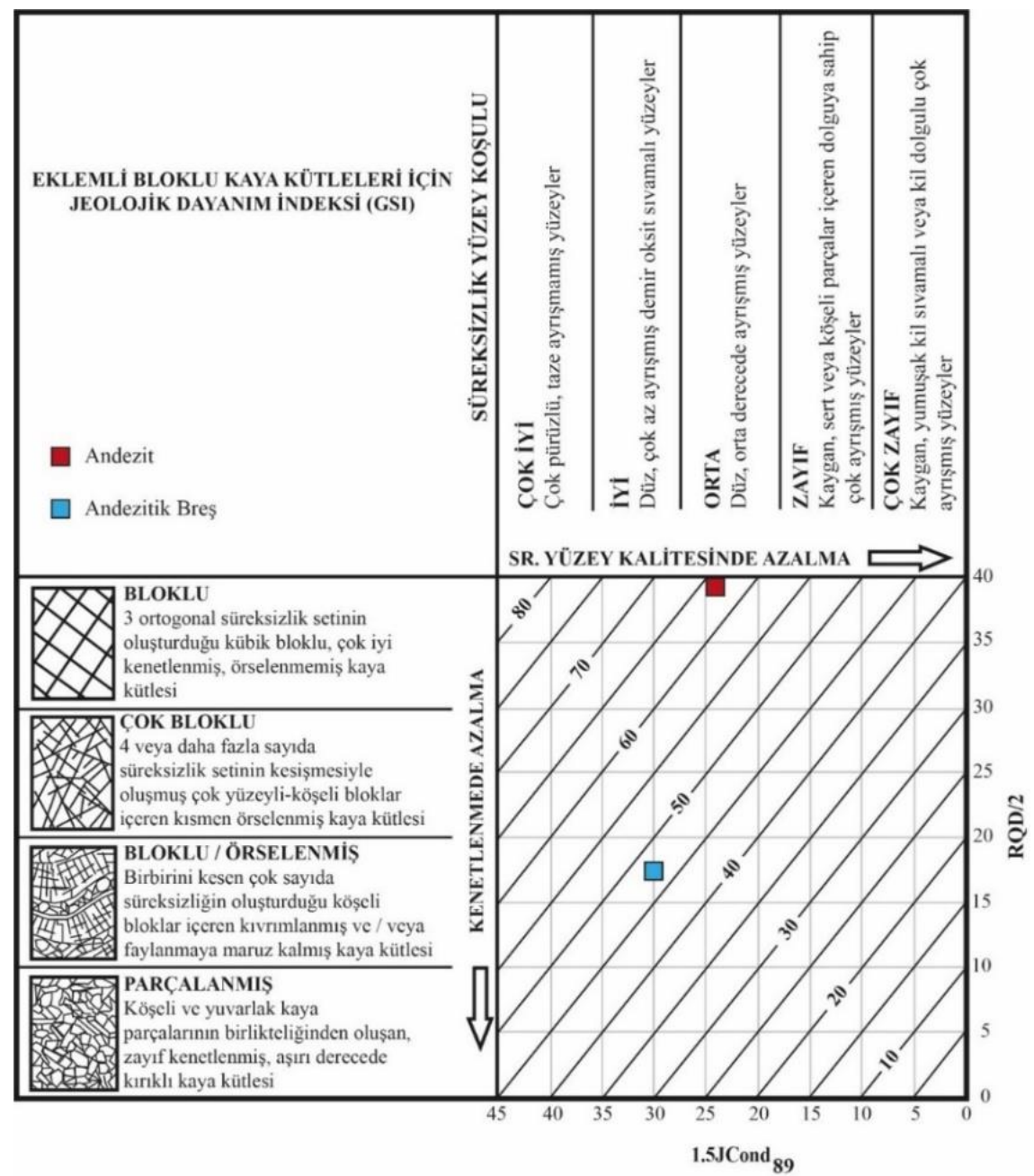

Şekil 5. Andezit ve andezitik breş kaya kütlelerinin Hoek vd. (2013) tarafindan önerilen GSI abağına göre değerlendirilmesi 
Atık barajı eksen yeri ve rezervuar alanı kazıları için kaya kütlelerinde kontrollü patlatma veya mekanik kazı uygulanacağı için örselenme faktörü (D) 0.7 olarak alınmıştır. Andezit ve andezitik breşin dinamik Poisson oranlarını belirlemek amacıyla yapılan sismik çalışmalarda ortalama Poisson oranları andezitler için 0.16 , andezitik breşler için ise 0.33 olarak belirlenmiştir (Tablo
2). Dinamik Poisson oranları hesaplanırken, Bowles (1996) tarafindan önerilen eşitlik (1) kullanılmıştır.

$v=\left(V_{p}^{2}-2 x V_{s}^{2}\right) /\left(2 x V_{p}^{2}-2 x V_{s}^{2}\right)$

Burada; $\mathrm{V}_{\mathrm{p}}$ : P dalga hızı, $\mathrm{V}_{\mathrm{s}}$ : S dalga hızıdır.

Tablo 2. Kaya kütlelerine ait $\mathrm{V}_{\mathrm{p}}, \mathrm{V}_{\mathrm{s}}$ hızları ve poisson oranı değerleri

\begin{tabular}{clccc}
\hline \multirow{2}{*}{ Serim No } & \multicolumn{1}{c}{ Birim } & $\mathrm{V}_{\mathrm{p}}(\mathrm{m} / \mathrm{s})$ & $\mathrm{V}_{\mathrm{s}}(\mathrm{m} / \mathrm{s})$ & $\begin{array}{c}\text { Poisson oranı } \\
(\mathrm{v})\end{array}$ \\
\hline \multirow{2}{*}{ 1. Hat } & Andezitik Breş & 1320 & 630 & 0.32 \\
& Andezit & 2400 & 1500 & 0.18 \\
\hline \multirow{2}{*}{ 2. Hat } & Andezitik Breş & 900 & 480 & 0.30 \\
& Andezit & 2350 & 1470 & 0.18 \\
\hline \multirow{2}{*}{ 3. Hat } & Andezitik Breş & 1550 & 760 & 0.34 \\
& Andezit & 2000 & 1290 & 0.14 \\
\hline \multirow{2}{*}{ 4. Hat } & Andezitik Breş & 1100 & 560 & 0.33 \\
& Andezit & 2600 & 1640 & 0.17 \\
\hline \multirow{2}{*}{ 5. Hat } & Andezitik Breş & 1400 & 650 & 0.36 \\
& Andezit & 2500 & 1560 & 0.18 \\
\hline \multirow{2}{*}{ 6. Hat } & Andezitik Breş & 1370 & 680 & 0.34 \\
& Andezit & 2040 & 1295 & 0.16 \\
\hline \multirow{2}{*}{ 7. Hat } & Andezitik Breş & 950 & 460 & 0.35 \\
& Andezit & 2040 & 1360 & 0.10 \\
\hline
\end{tabular}

\section{Bulgular ve Tartışma}

\section{1. Kaya Kütlelerinin Taşıma Kapasitesi}

Baraj eksen yerindeki andezit ve andezitik breşlerin taşıma kapasitesi hesaplamalarında farklı araștırmacilar tarafindan önerilen ampirik eşitlikler kullanılmıştır.

Kulhawy ve Carter (1992) tarafindan önerilen Nihai taşıma kapasitesi $\left(\mathrm{q}_{\mathrm{u}}\right)$ eşitlik (2) de verilmiş olup, eşitlikteki $\mathrm{m}_{\mathrm{b}}$, $\mathrm{s}$, a parametreleri HoekBrown kaya kütle sabitleridir. $\sigma_{\mathrm{ci}}$ ise kaya malzemesinin tek eksenli sıkışma dayanımıdır.

$\mathrm{q}_{\mathrm{u}}=\sigma_{c i}\left[s^{a}+\left(m_{b} s^{a}+s\right)^{a}\right]$

Wyllie (1992) tarafından önerilen izin verilebilir taşıma kapasitesi ( $\mathrm{q}_{\mathrm{a}}$ ) eşitlik (3) te verilmiş olup, bu eşitlikte F: güvenlik katsayısı (bu çalışma için 3 alınmıştır), $C_{\mathrm{f} 1}$ ise temel şekline bağlı düzeltme faktörüdür (şerit temel için 1 alınmıştır).

$\mathrm{q}_{\mathrm{a}}=\frac{C_{f 1} s^{-0,5} \sigma_{c i}\left[1+\left(m_{b} s^{-0,5}+1\right)^{0.5}\right]}{F}$

$\mathrm{Bu}$ eşitliklerden elde edilen kaya kütlelerinin taşıma kapasitesi değerleri Tablo 3'de verilmiştir.
Tablo 3. Kaya kütlesinin nihai ve izin verilebilir taşıma kapasitesi

\begin{tabular}{|c|c|c|}
\hline Yazarlar & $\begin{array}{c}\text { Eşitlik } \\
\text { No }\end{array}$ & $\begin{array}{c}\text { Kaya Kütlesi } \\
\text { Andezit }\end{array}$ \\
\hline Kulhawy ve Carter (1992) & 2 & $31.07(\mathrm{MPa})$ \\
\hline Wyllie (1992) & 3 & $10.44(\mathrm{MPa})$ \\
\hline
\end{tabular}

Yapılan hesaplamalara göre andezit kaya kütlesinin nihai taşıma kapasitesi $31.07 \mathrm{MPa}$, izin verilebilir taşıma kapasitesi ise $10.44 \mathrm{MPa}$ olarak belirlenmiştir. İnceleme alanında andezitik breşler sıyırılıp, baraj gövdesinin oturacağı temel kaya andezit kaya kütlesi olacağı için hesaplamalarda andezitik breşler dikkate alınmamıştır.

\section{2. Kaya Kütlelerinin Kazılabilirliği}

Baraj eksen yeri ve rezervuar alanının kazısı esnasında, yap1 maliyetini etkileyen en önemli faktörlerden birisi de kayaçların kazılabilirliğinde hangi yöntemin kullanılacağıdır (Gurocak vd., 2008; Kaya vd., 2011). Bu sebeple, kazı yapılacak kayaçların kazılabilirlik durumlarının iyi değerlendirilmesi gerekmektedir. Bu çalışmada, andezit ve andezitik breş kayaçlarının kazılabilirliği Tsiambos ve Saroglu (2010) tarafından önerilen kazılabilirlik sınıflama abağı yardımı ile belirlenmiştir (Şekil 6). 


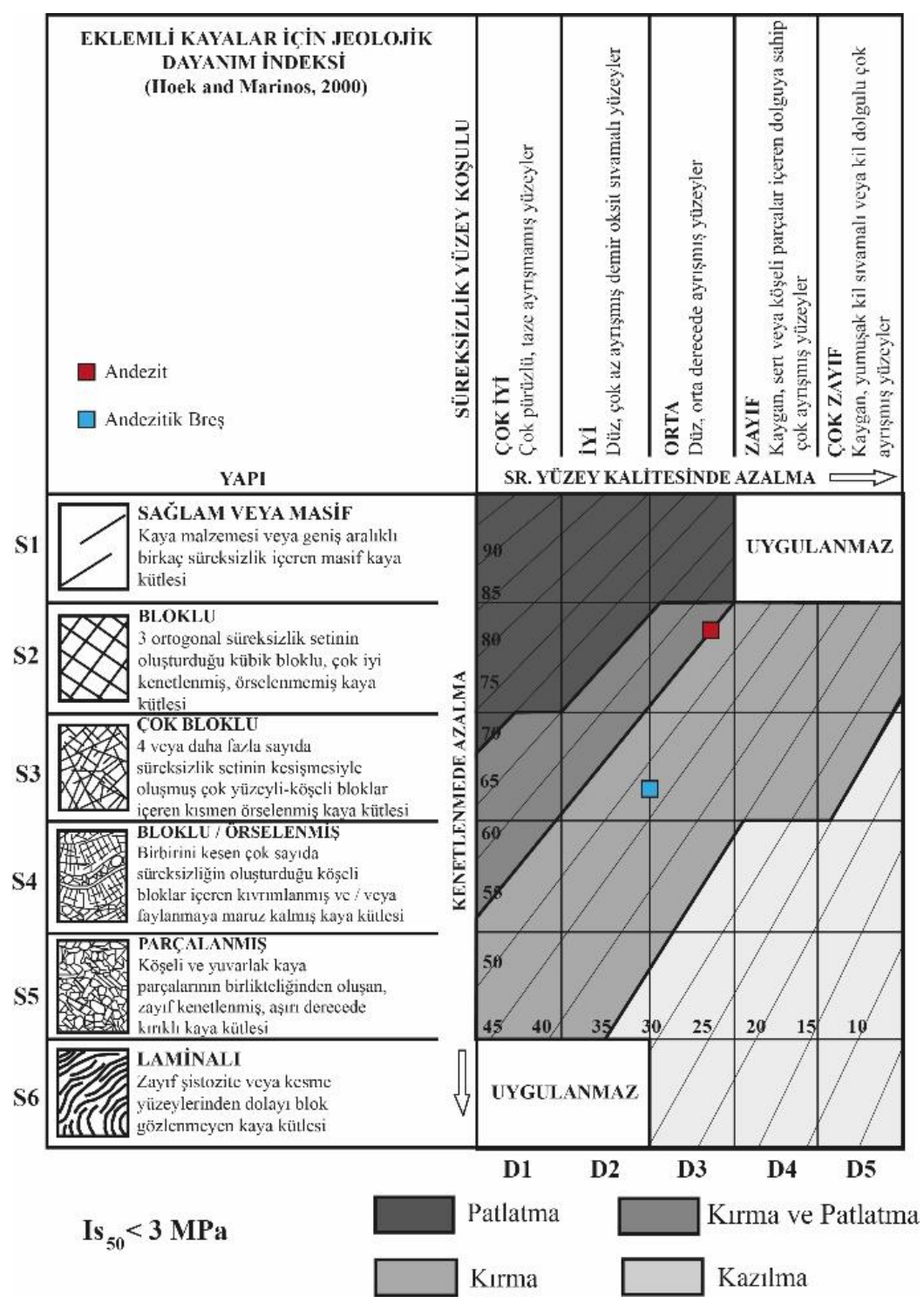

Şekil 6. Kazılabilirliğin belirlenebilmesi için önerilen abak (Tsiambos ve Saroglu, 2010)

Hem baraj eksen yeri, hem de rezervuar alanında yapılacak kazılarda, özellikle baraj ekseninde, mühendislik özellikleri andezite göre zayıf olan andezitik breşin tamamen kazılması gerekmektedir. Şekil 6'daki abak incelendiğinde, andezitler için "kırma ve patlatma" yönteminin birlikte kullanılması önerilirken, andezitik breşler için "kırma yöntemi" kullanımının uygun olacağı öngörülmektedir.

\section{3. Kaya Kütlelerinin Geçirimliliği}

Geçirimlilik eksen yerinde yapılan basınçlı su testleri ve sonlu elemanlar tabanlı sizma analizleri ile değerlendirilmiştir. Öncelikle, inceleme alanında açılmış olan sondaj kuyularında $2 \mathrm{~m}$ 'lik deney zonlarında yapılan basınçlı su deneylerine ait veriler değerlendirilerek kaya kütlelerinin Lugeon (Lugeon, 1933) değerleri belirlenmiştir. Elde edilen Lugeon değerleri Şekil 7'de verilen histogramlar ile değerlendirilmiş ve geçirimlilik sınıflarına göre yüzde dağılımları ise Tablo 4' de verilmiştir. Elde edilen deney verilerine göre andezitler az geçirimli-geçirimli (ortalama 4.3 Lugeon), andezitik breşler ise az geçirimligeçirimsizdir (Ortalama 2.1 Lugeon). Andezitik breşler tamamen kazı ile kaldırıldığı için, analizlerde andezitlerin ortalama $\mathrm{K}$ değeri olan $2.99 \times 10^{-5}$ değeri kullanılmıştır.

Sadece sondaj noktaları ile sinırlı olan bu veriler sonlu elemanlar yöntemi ile değerlendirilerek baraj eksen yeri için sızma analizleri yapılmıştır. $\mathrm{Bu}$ analizde 2-3m kalınlığa sahip olan andezitik breşler kazılarak, baraj ekseninin andezitler üzerine oturduğu kabul edilmiştir. RS2 (Rocscience, 2019) programında kullanılan girdi parametreleri Tablo 5'de verilmiş olup, eksen yeri Sonlu Elemanlar Yöntemi kullanılarak ile modellenmiştir (Şekil 8). 

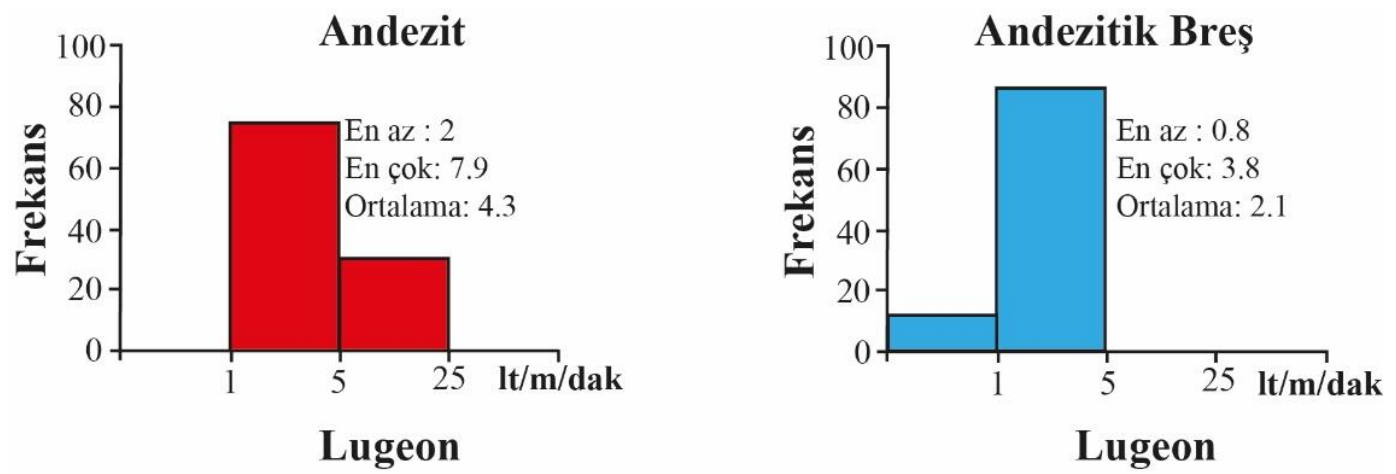

Şekil 7. Kaya kütlelerine ait Lugeon değerlerinin dağılımı ve istatistiksel değiş̧imi

Tablo 4. Lugeon (1933)'un geçirimlilik sınıflamasına göre çalışma alanındaki andezit ve andezitik breşlerin $\%$ dağılımı ve sınıflandırılması.

\begin{tabular}{cccc}
\hline $\begin{array}{c}\text { Lugeon sınır değerleri } \\
(1 / \mathrm{m} / \text { dak })\end{array}$ & Kaya Sınıfi & $\begin{array}{c}\text { Andezit } \\
(\%)\end{array}$ & $\begin{array}{c}\text { Andezitik Breş } \\
(\%)\end{array}$ \\
\hline$<1$ & Geçirimsiz & 0 & 13 \\
\hline $1-5$ & Az Geçirimli & 75 & 87 \\
\hline $5-25$ & Geçirimli & 25 & 0 \\
\hline$>25$ & Çok Geçirimli & 0 & 0 \\
\hline
\end{tabular}

Yapılması planlanan atık barajı temel kayası olan andezitlerin az-geçirimli özellikte olması nedeni ile atık barajından meydana gelecek kaçakların yeraltı sularına etkisi kaçınılmazdır. Andezit ve andezitik breşler akifer özelliği göstermemesine rağmen, kaya kütlelerinde bulunan çatlak sistemleri atık barajında toplanacak atık suların yeraltı suyuna karışmasında etkili olacaktır. RS2 ile yapılan analiz modelinde 8 dügüm noktalı, dörtgen dereceli ağ sistemi kullanılmış olup (Şekil 8 ), eksen yerinde, rezervuar alanının tamamen atık su ile dolu olduğu durum için yapılan sızma analizi (Şekil 9) sonucunda elde edilen düşey geçirimlilik değerleri $1.5 \times 10^{-6} \mathrm{~m} / \mathrm{s}$ ile $2.99 \times 10^{-5} \mathrm{~m} / \mathrm{s}$ arasında değişim göstermektedir. Bu durum eksen yeri ve göl alanında yayılım gösteren kaya kütlesinin geçirimli özellikte olduğunu ifade etmektedir. Ayrıca yaklaşık 10m derinlikte çizilen deşarj kesitinde (Şekil 9) meydana gelen su kaçakları $2.35 \times 10^{-16} \mathrm{~m}^{3} / \mathrm{s}$ ile $5.22 \times 10^{-17} \mathrm{~m}^{3} / \mathrm{s}$ arasında değişmektedir. $\mathrm{Bu}$ su sızıntıları kaya kütlesi akifer özellikte olmadığı için oldukça küçük değerlerdedir. Ancak bu durum meydana gelecek olas1 bir sizma durumunda bile yeraltı suyunun kirlenmesine neden olacak değerdedir. $\mathrm{Bu}$ nedenle, atık baraj yerinde sizıntıların önlenebilmesi amacıyla ek önlemlerin alınması gerekmektedir.

Tablo 5. Sayısal analizde kullanılan parametreler

\begin{tabular}{|c|c|c|c|c|c|c|c|c|c|c|c|}
\hline \multirow{2}{*}{ Andezit } & \multirow{2}{*}{ GSI } & \multirow{2}{*}{$\begin{array}{c}\sigma_{\mathrm{ci}} \\
(\mathrm{MPa})\end{array}$} & \multirow{2}{*}{$\mathrm{mi}$} & \multirow{2}{*}{$\begin{array}{c}\gamma \\
\left(\mathrm{kN} / \mathrm{m}^{3}\right)\end{array}$} & \multirow{2}{*}{$v$} & \multirow{2}{*}{$\mathrm{D}$} & \multirow{2}{*}{$\underset{(\mathrm{m} / \mathrm{sn})}{\mathrm{K}}$} & \multirow{2}{*}{$\begin{array}{c}\mathrm{E}_{\mathrm{m}} \\
(\mathrm{GPa})\end{array}$} & \multicolumn{3}{|c|}{$\begin{array}{l}\text { Hoek - Brown } \\
\text { sabitleri }\end{array}$} \\
\hline & & & & & & & & & $\mathrm{mb}$ & $\mathrm{S}$ & $\mathrm{a}$ \\
\hline Eksen Yeri & 64 & 54 & 25 & 26.87 & 0.16 & 0.7 & $2.99 \times 10^{-5}$ & 5.39 & 3.45 & 0.005 & 0.502 \\
\hline $\begin{array}{l}\text { Yenilme } \\
\text { Kriteri }\end{array}$ & \multicolumn{8}{|c|}{ Genelleştirilmiş Hoek-Brown } & \multicolumn{3}{|c|}{$\begin{array}{l}\text { Rezidüel Hoek-Brown } \\
\text { sabitleri }\end{array}$} \\
\hline Malzeme Tipi & \multicolumn{8}{|c|}{ Plastik } & $\mathrm{mb}$ & $\mathrm{s}$ & $\mathrm{a}$ \\
\hline $\begin{array}{l}\text { Hidrolik } \\
\text { Model }\end{array}$ & \multicolumn{8}{|c|}{ Basit } & 1.72 & 0.002 & 0.502 \\
\hline
\end{tabular}




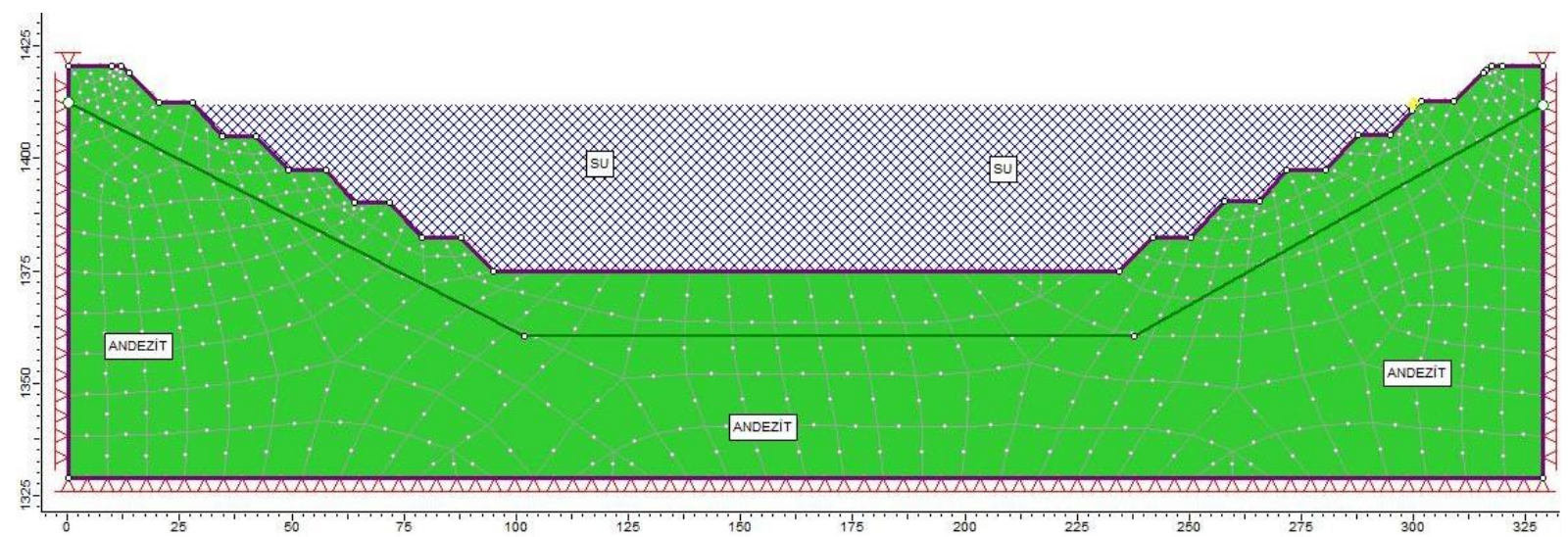

Şekil 8. Atık barajı II eksen yerinin sonlu elemanlar ağ sistemi ile modellenmesi

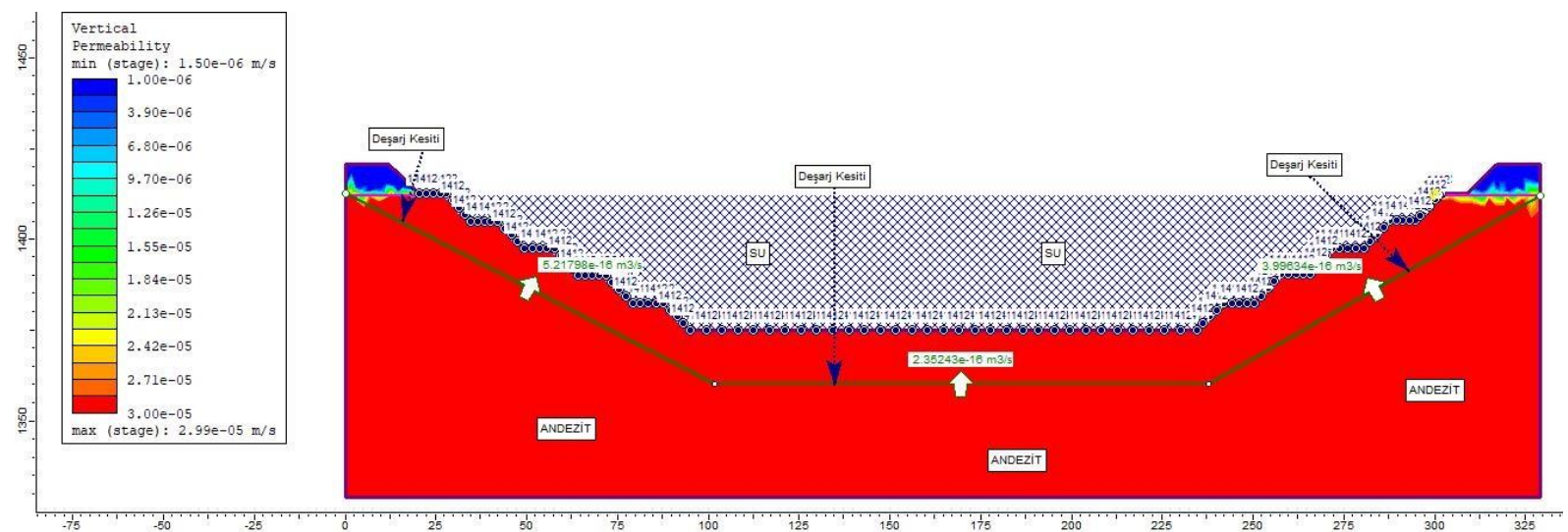

Şekil 9. Atık barajı II için yapılan sonlu elemanlar sızma analizi

\section{4. Atık Baraj Yeri ve Rezervuar Alanında Geçirimsizlik Uygulamaları}

Atık baraj yeri rezervuar alanında yapılan sızma analizi değerlendirildiğinde, kaya kütlesinin geçirimli olması yeraltı suyu kirlenmesinin kaçınılmaz olduğu göstermektedir. $\mathrm{Bu}$ durumu önlemek için baraj eksen yerinde ve rezervuar alanında önlem alınması gerekmektedir.
Geçirimsizliği sağlamak amacıyla ilk önce ince bir kil tabakas $135-40 \mathrm{~cm})$ serilmesi ve sıkıştırılması (Şekil 10) sonucunda sızmanın kontrol altına alınıp, alınamadığını belirlemek için yeniden sayısal analizler yapılmıştır.

Sayısal analizlerde andezit kaya kütlesi için Tablo 5'deki veriler kullanılmış olup, sıkıştırılmış kilin mühendislik özellikleri ise Tablo 6'de verilmiştir.

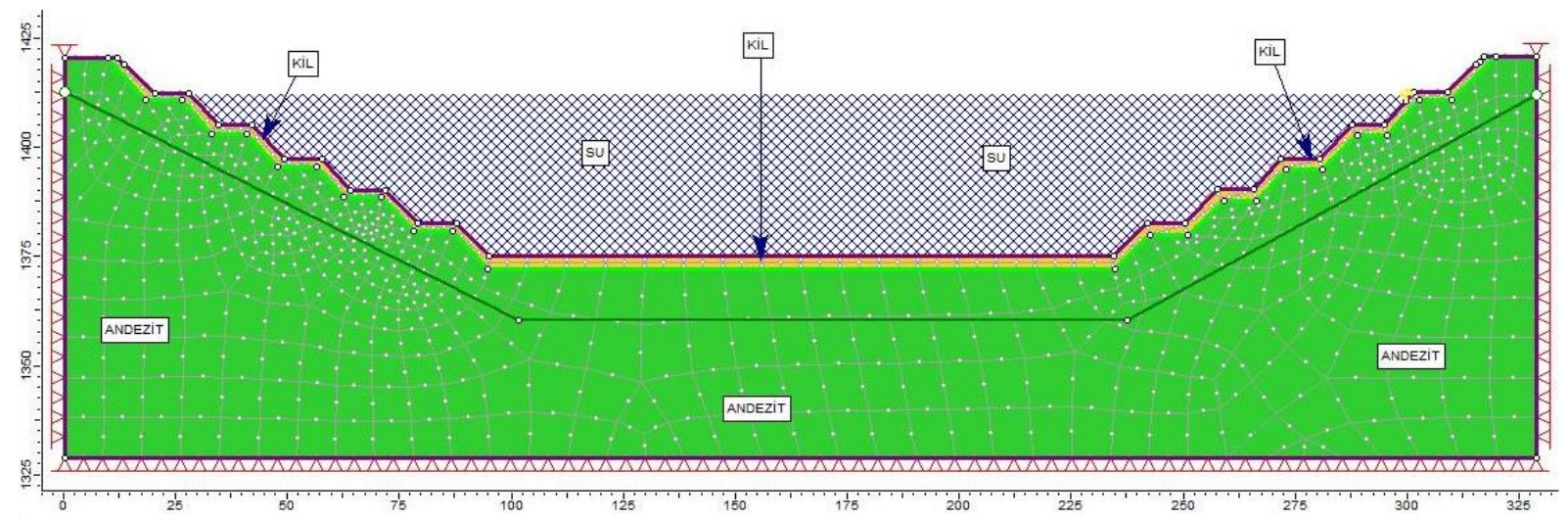

Şekil 10. Atık baraj1 eksen yerinin iyileştirme sonrası (kil sıkıştırma) sonlu elemanlar ağ sistemi ile modellenmesi 
Tablo 6. Rezervuar alanına serilecek kilin malzeme özellikleri

\begin{tabular}{cccccccccc}
\hline & $\begin{array}{c}\gamma \\
\left(\mathrm{kN} / \mathrm{m}^{3}\right)\end{array}$ & $\begin{array}{c}\mathrm{E} \\
(\mathrm{MPa})\end{array}$ & $v$ & $\begin{array}{c}\Phi \\
(\mathrm{Pik})\end{array}$ & $\begin{array}{c}\mathrm{c}(\mathrm{Pik}) \\
(\mathrm{MPa})\end{array}$ & $\begin{array}{c}\Phi \\
(\text { Art1k })\end{array}$ & $\begin{array}{c}\mathrm{c}(\text { Artık }) \\
(\mathrm{MPa})\end{array}$ & $\mathrm{K}_{\mathrm{s}}$ & $\mathrm{K}_{2} \backslash \mathrm{K}_{1}$ \\
\hline Kil & 15.4 & 3.8 & 0.4 & $26^{\circ}$ & 0.035 & $16^{\circ}$ & 0.012 & $1.24 \times 10^{-9}$ & 1 \\
\hline
\end{tabular}

Analiz sonucunda elde edilen düşey geçirimlilik değerleri $5.00 \times 10^{-11} \mathrm{~m} / \mathrm{s}$ olmuştur. $\mathrm{Bu}$ durum, yüzeyde yapılan kil sıkıştırma sonucunda geçirimsiz bir taban oluşturduğunu (T.C. Resmi Gazete, 2015) ve barajdan olabilecek sizıntıların engellendiğini ifade etmesine (Şekil 10) ve yaklaşı $10 \mathrm{~m}$ derinlikte çizilen deşarj kesitinde (Şekil 11) meydana gelen atık su kaçakları $1.69 \times 10^{-17} \mathrm{~m}^{3} / \mathrm{s}$ ile $2.21 \times 10^{-16} \mathrm{~m}^{3} / \mathrm{s}$ gibi sifira yakın değerlere düşmesine karşın, hala olası bir sızmanın meydana gelebileceğini göstermektedir.

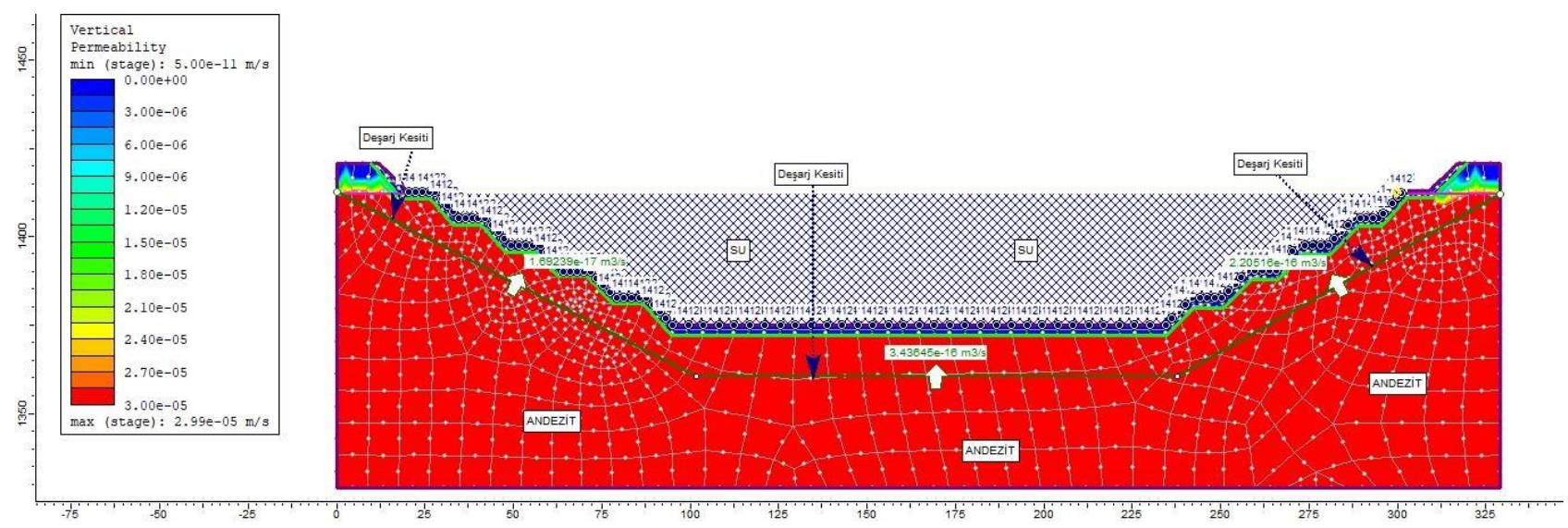

Şekil 11. Atık barajında iyileştirme sonrası sonlu elemanlar sızma analizi

$\mathrm{Bu}$ sızıntıları önleyebilmek için sıkıştırılan doğal kil tabakanın üzerine daha güvenli bir geçirimsizlik ortamı sağlanması amacı ile sırasıyla jeosentetik kil membran, jeomembran ve drenaj jeokompozit serilmelidir. $\mathrm{Bu}$ uygulamalardan sonra rezervuar alanı ve eksen yeri tamamiyla geçirimsiz hale getirilmiş olacak olup, olası bir yeraltı suyu kirlenmesi engellenmiş olacaktır.

\section{Sonuçlar}

$\mathrm{Bu}$ çalışmada, inşa edilmesi planlanan Gümüştaş Atık Depolama Baraj1 II'nin eksen yeri ve rezervuar alanı mühendislik jeolojisi açısından incelenmiştir. İnceleme alanında Eosen yaşlı Alibaba Formasyonu'nun üst kısımlarında bulunan andezit ve andezitik breşler yüzeyleme vermektedir. Andezitlerin üzerinde bulunan andezitik breşlerin kalınlıklarının 2-3m olması ve rezervuar alanının hacimsel olarak genişlemesinden dolayı tamamen kazılarak kaldırılması öngörülmektedir.

Andezit ve andezitik breşlerin kazılabilirlikleri Tsiambos ve Saroglu'na göre değerlendirilmiş olup, andezitik breşlerin "kırma yöntemi" ile andezitlerin ise "kırma ve patlatma" yöntemi ile kazılabileceği belirlenmiştir. Andezitlerin nihai taşıma kapasitesi değerleri $31.07 \mathrm{MPa}$, izin verilebilir taşım kapasitesi ise $10.44 \mathrm{MPa}$ olarak belirlenmiş ve taşıma kapasitesi açısından herhangi bir problem yaşanmayacağ 1 sonucuna varılmıştır. Atık barajı eksen yeri ve rezervuar alanında yapılan sızma analizleri (rezervuar alanı tamamen atık ile dolu olması durumunda) andezit kaya kütlesinin geçirimliliğinin $1.5 \times 10^{-6} \mathrm{~m} / \mathrm{s}$ ile $2.99 \times 10^{-5} \mathrm{~m} / \mathrm{s}$ arasında değiştiğini göstermiştir. $\mathrm{Bu}$ değerler atık barajında biriktirilecek olan atığın yeraltı suyunu kirletebileceğini ve geçirimsizliği sağlamak amacıyla ek önlemlerin alınması gerektiğini göstermiştir. Olumsuzluğun Baraj eksen yeri ve rezervuar alanına $35-40 \mathrm{~cm}$ kalınlığında kil tabakası serilip sıkıştırılarak, bu sızma problemini ne ölçüde engellenebileceğini belirlemek amaciyla yapılan sayısal analizler sonucunda geçirimlilik değeri $5 \times 10^{-11} \mathrm{~m} / \mathrm{s}$ olarak belirlenmiştir. Ayrıca, $10 \mathrm{~m}$ derinlikte çizilen deşarj kesitinde meydana gelen atık su kaçaklarına ait deşarj değerleri $1.69 \times 10^{-17} \mathrm{~m}^{3} / \mathrm{s}$ ile $3.44 \times 10^{-}$ ${ }^{16} \mathrm{~m}^{3} / \mathrm{s}$ arasında değişmektedir. Bu değerler çok 
düşük değerler olmasına rağmen, hala olası bir sızmanın meydana gelebileceğini göstermektedir. $\mathrm{Bu}$ nedenle, uygulanan doğal kil sıkıştırmanın üstüne sirasıla jeosentetik kil membran, jeomembran ve drenaj jeokompozit serilmesi ve böylece ortamın tamamen geçirimsiz duruma getirilmesi önerilmiştir. Baraj eksen yeri ve rezervuar alanında yapılacak bu uygulamalardan sonra herhangi sızmanın ve dolayısıyla herhangi bir yeraltı suyu kirlenmesinin oluşması engellenmiş olacaktır.

\section{Katkı Belirtme}

Yazarlar, bu çalışmayı destekleyen, çalışma süresince bütün olanaklarından yararlandığ Gümüştaş Madencilik A.Ş.'ye, yardımlarını esirgemeyen Genel Koordinatör Erdal Güldoğan'a, Uğur Ölgen ve Korhan Çubukçu'ya teşekkür eder.

\section{Kaynaklar}

Alemdag, S., Gurocak, Z., Solanki, P. ve Zaman, M., 2008. Estimation of Bearing Capacity of Basalts at Atasu Dam Site, Turkey. Bulletin of Engineering Geology and the Environment, 67, 79-85.

Alemdag, S., 2015. Assessment of Bearing Capacity and Permeability of Foundation Rocks at the Gumustas Waste Dam Site, (NE Turkey) Using Empirical and Numerical Analysis. Arabian Journal of Geosciences, 8, 1099-1110.

Arslan, M. ve Aliyazıcıŏglu, I., 2001. Geochemical and Petrological Characteristics of the Kale (Gumushane) Volcanic Rocks: Implications for the Eocene Evolution of Eastern Pontide Arc Volcanism, Northeast Turkey. International Geology Review, 43, 595-610.

Bostanci, H.T., Alemdag, S., Gurocak, Z. ve Gokceoglu, C., 2018. Combination of Discontinuity Characteristics and GIS for Regional Assessment of Natural Rock Slopes in a Mountainous Area (NE Turkey). CATENA, $165,487-502$.

Bowles, J.E., 1996. Foundation Analysis and Design, (Fifth Ed.): New York, McGraw-Hill Inc. 1230p.

Bieniawski, Z.T., 1989. Engineering Rock Mass Classification: New York, Wiley Interscience, 251p.

Ersoy, H., Bulut, F., Ersoy, A.F. ve Berkün, M., 2008. Municipal Solid Waste Management and Practices in Coastal Cities of the Eastern Black Sea: A Case Study of Trabzon City, NE Turkey.
Bulletin of Engineering Geology and the Environment, 67(3), 321-333.

Ersoy, H., Karahan, M., Gelişli, K., Akgün, A., Anılan, T., Sünnetci, M.O. ve Yahşi B.K., 2019. Modelling of the Landslide-Induced Impulse Waves in the Artvin Dam Reservoir by Empirical Approach and 3D Numerical Simulation. Engineering Geology, 249, 112128.

Foyo, A., Sanchez, M. A. ve Tomillo, C., 2005. A Proposal for a Secondary Permeability Index Obtained from Water Pressure Tests in Dam Foundations. Engineering Geology, 77, 69-82.

Gurocak, Z., Alemdag, S. ve Zaman, M., 2008. Rock Slope Stability and Excavatability Assessment of Rocks at the Kapikaya Dam Site, Eastern Turkey. Engineering Geology, 96(1-2), 17-27.

Gurocak, Z. ve Alemdag, S., 2012. Assessment of Permeability and Injection Depth at the Atasu Dam Site (Turkey) Based on Experimental and Numerical Analyses. Bulletin of Engineering Geology and the Environment, 71, 221-229.

Gurocak, Z., Alemdag, S., Bostanci, H.T. ve Gokceoglu, C., 2017. Discontinuity Controlled Slope Failure Zoning for a Granitoid Complex: A fuzzy Approach. Rock Mechanics and Engineering, Volume 5: Surface and Underground Projects, CRC Press Taylor \& Francis Group, eBook ISBN: 978-1-317-481881, Pages 1-25.

Hoek, E., Carranza-Torres, C. T. ve Corkum, B., 2002. Hoek-Brown Failure Criterion-2002 Edition. In: Proceedings of the $5^{\text {th }}$ North American Rock Mechanics Symposium. Toronto, Canada 1, 267-273.

Hoek, E., Carter, T. G. ve Diederichs, M. S., 2013. Quantification of the Geological Strength Index Chart. $47^{\text {th }}$ US Rock Mechanics and Geomechanics Symposium, San Francisco, USA.

ISRM (International Society for Rock Mechanics), 2007. In: Ulusay R, Hudson JA (Eds.), The Complete ISRM Suggested Methods for Rock Characterization, Testing and Monitoring. Kazan Offset Pres, Ankara, 628 s.

Kanik, M. ve Ersoy, H., 2019. Evaluation of the Engineering Geological Investigation of the Ayvali Dam Site (NE Turkey). Arabian Journal of Geosciences, 12(3), 89.

Karaguzel, R. ve Kilic, R., 2000. The Effect of the Alteration Degree of Ophiolitic Melange on Permeability and Grouting. Engineering Geology, 57, 1-12. 
Kaya, A., Bulut, F., Alemdag, S., 2011. Applicability of Excavatability Classification Systems in Underground Excavations: An Example of Konakönü Tunnel, Trabzon, Turkey. Scientific Research and Essays, 6(25), 5331-5341.

Kaygusuz, A., Arslan, M., Siebel, W. ve Şen, C., 2011. Geochemical and $\mathrm{Sr}-\mathrm{Nd}$ Isotopic Characteristics of Post-Collisional Calc-Alkaline Volcanics in the Eastern Pontides (NE Turkey). Turkish Journal of Sciences, 20, 137-159.

Kulhawy, F.H. ve Carter, J.P., 1992. Settlement and Bearing Capacity of Foundations on Rock Masses and Socketed Foundations in Rock Masses. In: Bell F.G. (Ed.), Engineering in Rock Masses. Butterworth-Heinemann, Oxford, pp. 231-245.

Lugeon, M., 1933. Barrages et Geologic Methods de Recherche Terrasement et un Permeabilisation. Litrairedes Universite, Paris.

Maden Atıkları Yönetmeliği, 2015. T.C. Resmi Gazete, Sayı: 29417, 15 Temmuz 2015.

Moosavi, S.A., Goshtasbi, K., Kazemzadeh, E., Aloki Bakhtiari, H., Esfahani, M. R. ve Vali, J., 2012. Relationship Between Porosity and Permeability with Stress Using Pore Volume Compressibility Characteristic of Reservoir Rocks. Arabian Journal of Geosciences, 7(1), 231-239.

Noorzad, R. ve Manavirad E., 2012. Bearing Capacity of Two Close Strip Footings on Soft Clay Reinforced with Geotextile. Arabian Journal of Geosciences, 7(2), 623-639.
Rad, H. S., Mohitazar M. ve Dizadji M., 2013. Distinct Element Simulation of Ultimate Bearing Capacity in Jointed Rock Foundations. Arabian Journal of Geosciences, 6(11), 4427-4434.

Rocscience, 2007. Roclab v1.03 Rock Mass Strength Analysis Using the Generalized Hoek-Brown Failure Criterion. Rocscience Inc., Toronto, Ontario, Canada.

Rocscience, 2019. RS2 9.0 Finite Element Groundwater Seepage. Geomech Software and Res. Rocsci, Toronto.

Türkmen, S., Tağa, H. ve Özgüler, E., 2013. Effect of Construction Material on Dam Type Selection of the Büyük Karaçay Dam (Hatay, Turkey). Geotechnical and Geological Engineering, 31, 1137-1149.

Tsiambaos, G. ve Saroglou, H., 2010. Excavatability Assessment of Rock Masses Using the Geological Strength Index (GSI). Bulletin of Engineering Geology and the Environmental, 69(1), 13-27.

Wang, J.S.Y., Trautz, R.C., Cook, P.J., Finsterle, S., James, A.L. ve Birkholzer, J., 1999. Field Tests and Model Analyses of Seepage into Drift. Journal of Contaminant Hydrology, 38(1-3), 323-347.

Wyllie, D. C., 1992. Foundations on Rock: London, Chapman and Hall, 457p. 